\title{
Kinetics of the Reaction of Atomic Oxygen with Tetramethylsilane
}

\author{
Luying Ding and Paul Marshall" \\ Department of Chemistry, University of North Texas, P.O. Box 5068, Denton, Texas 76203-5068
}

Received: October 19, 1992; In Final Form: January 18, 1993

\begin{abstract}
The rate constant for $\mathrm{O}(2 \mathrm{p})^{3} \mathrm{P}_{\mathrm{J}}+\left(\mathrm{CH}_{3}\right)_{4} \mathrm{Si}$ has been measured using the flash photolysis/resonance fluorescence technique over the temperature range $380-700 \mathrm{~K}$. The results are described by $k=(5.1 \pm 0.7) \times 10^{-11}$ $\exp \left(-24.1 \pm 0.6 \mathrm{~kJ} \mathrm{~mol}^{-1} / R T\right) \mathrm{cm}^{3} \mathrm{~s}^{-1}$ where the uncertainties represent $\pm 1 \sigma$ precision. The $95 \%$ accuracy interval for $k$ is about $\pm 15 \%$. The results show that the activation energy $E_{\mathrm{a}}$ is reduced compared to other hydrocarbons by the trimethylsilyl group. A series of $\mathrm{O}+$ primary $\mathrm{C}-\mathrm{H}$ bond reactions are considered, and possible correlations between $E_{\mathrm{a}}$ and the $\mathrm{C}-\mathrm{H}$ bond energy and hydrocarbon ionization potential are discussed.
\end{abstract}

\section{Introduction}

The flash photolysis/resonance fluorescence (FP-RF) method has been employed to carry out the first investigation of the reaction

$$
\mathrm{O}+\left(\mathrm{CH}_{3}\right)_{4} \mathrm{Si} \rightarrow \text { products }
$$

from 380 to $700 \mathrm{~K}$. The aim is to characterize how substitution of $\mathrm{H}$ in $\mathrm{CH}_{4}$ by a trimethylsilyl group affects the reactivity of the remaining $\mathrm{C}-\mathrm{H}$ bonds toward atomic oxygen, $\mathrm{O}(2 \mathrm{p})^{3} \mathrm{P}_{\mathrm{j}}$, for comparison with hydrocarbon reactions.

We are interested in the lability of methyl groups attached to silicon in two contexts. First, it has been established by FP-RF and discharge flow experiments that trimethylsilane is more reactive toward $O$ than silane, ${ }^{1-3}$ and possible reaction at the $\mathrm{C}-\mathrm{H}$ bonds might contribute toward the overall consumption of O. Second, the reaction

$$
\mathrm{O}+\mathrm{Si}_{2}\left(\mathrm{CH}_{3}\right)_{6} \rightarrow \text { products }
$$

has been attributed to $\mathrm{O}$ atom insertion into the $\mathrm{Si}-\mathrm{Si}$ bond, ${ }^{4}$ and again we would like to quantify the possible $\mathrm{C}-\mathrm{H}$ bond reactivity. This reactivity might well be greater than in $\mathrm{CH}_{4}$, because of the $\mathrm{C}-\mathrm{H}$ bond weakening influence of the $\mathrm{Si}\left(\mathrm{CH}_{3}\right)_{3}$ group. $^{5}$ The small $\mathrm{C}-\mathrm{H}$ bond strength, $\mathrm{D}$, in $\left(\mathrm{CH}_{3}\right)_{4} \mathrm{Si}$ broadens the range of $D$ in $\mathrm{H}$ atom abstraction reactions which have been investigated and thus permits a correlation of the activation energy with $D$.

\section{Experimental Technique}

Tetramethylsilane (Aldrich, $99.9+\%$ ) was degassed by freezepump-thaw cycles, and other materials were used as described earlier. ${ }^{2}$ The reactor and general FP-RF method have been discussed previously, ${ }^{6.7}$ as well as details of the generation and detection of atomic $0 .^{2}$ In summary, $\mathrm{O}$ atoms are formed by flash photolysis of a precursor, either $\mathrm{O}_{2}$ or $\mathrm{SO}_{2}$ here, and are monitored by time-resolved atomic resonance fluorescence at a wavelength of $130 \mathrm{~nm} .^{8}$ The fluorescence is excited by a microwave-powered discharge lamp and is observed through magnesium fluoride optics with a solar-blind photomultiplier tube. Current pulses from individual photons are amplified and then counted by a computer-controlled multichannel scaler.

After generation in the reaction zone $O$ atoms are lost over 1-100 ms because of (i) reaction 1 and (ii) diffusion and recombination with the precursor, described by $k_{\text {diff. }}$. The experiments were carried out in a large excess of Ar bath gas to maintain thermal equilibrium and to slow diffusive losses. Because diffusion of $O$ to the walls of the reactor is slower than consumption by chemical reactions, the reaction zone is effectively wall-less.

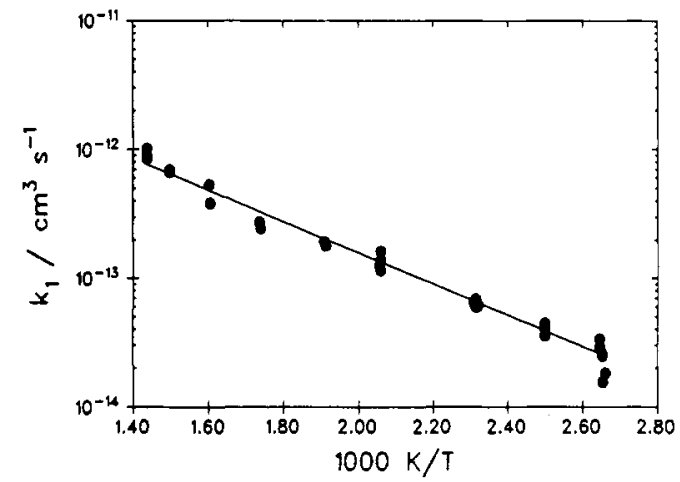

Figure 1. Arrhenius plot for the reaction $\mathrm{O}+\left(\mathrm{CH}_{3}\right)_{4} \mathrm{Si}$.

The temperature, $T$, of the reaction zone is measured at the beginning and end of each experiment with a thermocouple previously corrected for radiation errors. The uncertainty in $T$ is estimated conservatively to be $\sigma_{T} / T \approx 2 \%$. An experiment involves monitoring [O] as a function of time at zero reactant concentration and typically five values of $\left[\left(\mathrm{CH}_{3}\right)_{4} \mathrm{Si}\right] \gg[\mathrm{O}]$, at a constant precursor concentration and a constant total pressure, $P$, i.e. constant $k_{\text {diff. }}$. Under these pseudo-first-order conditions

$$
[\mathrm{O}]=[\mathrm{O}]_{0} \exp \left(-k_{\mathrm{ps} 1} t\right)
$$

where $t$ is the time after the photolysis flash and $k_{\mathrm{ps} 1}$ is the pseudofirst-order decay constant:

$$
k_{\mathrm{ps} 1}=k_{1}\left[\left(\mathrm{CH}_{3}\right)_{4} \mathrm{Si}\right]+k_{\mathrm{diff}}
$$

$k_{\mathrm{ps} 1}$ is obtained by nonlinear least-squares fitting to the fluorescence decay traces, ${ }^{9}$ and $k_{1}$ and its statistical uncertainty $\sigma_{k l}$ are obtained from the slopes of weighted linear plots ${ }^{10}$ of $k_{\mathrm{ps} \text { I }}$ vs [Si$\left.\left(\mathrm{CH}_{3}\right)_{4}\right]$, with all other conditions held constant.

\section{Results}

Preliminary checks showed that no fluorescence is detected in the absence of added $\mathrm{O}$ atom precursor, i.e. no fluorescence that might interfere with the experiments is excited from any photolysis fragments of $\left(\mathrm{CH}_{3}\right)_{4} \mathrm{Si}$.

Thirty-three measurements of $k_{1}$ as a function of $T$ are summarized in Table I, together with the experimental parameters $P$, flash lamp discharge energy $F$, precursor type and concentration, and the gas residence time within the reactor before photolysis, $\tau_{\text {res. }}$ The data at $377 \mathrm{~K}$ are the most scattered (with a standard deviation of about $23 \%$ of $k_{1}$ ), which might reflect the influence of some or all of the following: secondary chemistry, 
TABLE I: Summary of Rate Constant Measurements for $\mathrm{O}+\left(\mathrm{CH}_{3}\right)_{4} \mathrm{Si}$

\begin{tabular}{|c|c|c|c|c|c|c|c|}
\hline$T, \mathrm{~K}$ & $P$, mbar & $\tau_{\mathrm{res}, \mathrm{S}}$ & $F, \mathrm{~J}$ & {$\left[\mathrm{O}_{2}\right], 10^{16} \mathrm{~cm}^{-3}$} & {$\left[\mathrm{SO}_{2}\right], 10^{15} \mathrm{~cm}^{-3}$} & {$\left[\left(\mathrm{CH}_{3}\right)_{4} \mathrm{Si}\right]_{\max }, 10^{15} \mathrm{~cm}^{-3}$} & $k_{1} \pm \sigma_{k 1}, 10^{-14} \mathrm{~cm}^{3} \mathrm{~s}^{-1}$ \\
\hline 376 & 133 & 1.0 & 4.05 & & 5.81 & 3.05 & $1.82 \pm 0.04$ \\
\hline 377 & 66.7 & 1.0 & 1.25 & & 5.83 & 3.07 & $1.56 \pm 0.04$ \\
\hline 377 & 66.7 & 1.0 & 2.45 & & 5.83 & 3.07 & $2.49 \pm 0.05$ \\
\hline 377 & 66.7 & 1.0 & 5.00 & & 5.83 & 3.07 & $2.56 \pm 0.10$ \\
\hline 378 & 68.0 & 1.0 & 2.45 & 1.54 & & 3.06 & $2.85 \pm 0.45$ \\
\hline 378 & 66.7 & 2.0 & 4.05 & & 5.96 & 3.13 & $2.86 \pm 0.06$ \\
\hline 378 & 100 & 2.0 & 4.05 & & 6.08 & 3.18 & $2.92 \pm 0.18$ \\
\hline 378 & 133 & 2.0 & 4.05 & & 6.15 & 3.22 & $3.36 \pm 0.11$ \\
\hline 400 & 66.7 & 1.0 & 2.45 & & 5.43 & 1.62 & $3.55 \pm 0.36$ \\
\hline 400 & 66.7 & 1.0 & 4.05 & & 5.43 & 1.62 & $4.44 \pm 0.28$ \\
\hline 400 & 66.7 & 1.0 & 5.00 & & 5.43 & 1.62 & $4.02 \pm 0.08$ \\
\hline 431 & 133 & 1.0 & 4.05 & 1.13 & & 1.65 & $6.01 \pm 0.51$ \\
\hline 432 & 68.0 & 1.0 & 2.45 & 1.02 & & 1.49 & $5.95 \pm 1.14$ \\
\hline 432 & 68.0 & 1.0 & 5.00 & 1.02 & & 1.49 & $6.86 \pm 0.46$ \\
\hline 431 & 133 & 1.0 & 4.05 & & 4.80 & 1.33 & $6.21 \pm 0.44$ \\
\hline 433 & 66.7 & 1.0 & 4.05 & & 4.75 & 1.31 & $6.47 \pm 0.14$ \\
\hline 486 & 66.7 & 0.5 & 4.05 & 0.60 & & 1.34 & $13.8 \pm 1.7$ \\
\hline 486 & 133 & 1.0 & 4.05 & 0.61 & & 1.32 & $11.5 \pm 0.2$ \\
\hline 486 & 135 & 3.0 & 4.05 & 0.63 & & 1.97 & $16.3 \pm 0.4$ \\
\hline 487 & 66.7 & 1.0 & 4.05 & & 4.57 & 1.33 & $12.6 \pm 0.4$ \\
\hline 523 & 133 & 1.0 & 4.05 & & 4.24 & 1.24 & $18.0 \pm 1.6$ \\
\hline 524 & 68.0 & 1.0 & 4.05 & & 4.29 & 1.25 & $19.3 \pm 1.7$ \\
\hline 575 & 66.7 & 2.0 & 4.05 & & 3.44 & 1.04 & $24.6 \pm 1.4$ \\
\hline 576 & 101 & 0.9 & 4.05 & & 3.35 & 0.86 & $27.3 \pm 0.6$ \\
\hline 576 & 101 & 3.0 & 4.05 & & 3.83 & 0.96 & $27.5 \pm 1.0$ \\
\hline 623 & 201 & 1.0 & 4.05 & & 3.54 & 0.48 & $38.3 \pm 1.9$ \\
\hline 624 & 101 & 1.0 & 4.05 & & 3.22 & 0.47 & $52.9 \pm 2.9$ \\
\hline 668 & 133 & 1.0 & 4.05 & & 3.36 & 0.53 & $66.6 \pm 6.1$ \\
\hline 668 & 66.7 & 1.0 & 4.05 & & 3.33 & 0.53 & $69.2 \pm 6.0$ \\
\hline 696 & 66.7 & 0.5 & 4.05 & & 2.15 & 0.33 & $101 \pm 2$ \\
\hline 696 & 133 & 1.0 & 4.05 & & 3.23 & 0.32 & $84.7 \pm 4.2$ \\
\hline 696 & 133 & 2.9 & 4.05 & & 3.08 & 0.43 & $88.3 \pm 2.3$ \\
\hline 696 & 68.0 & 2.1 & 4.05 & & 3.24 & 0.31 & $87.3 \pm 4.3$ \\
\hline
\end{tabular}

uncertainty in $T$ (which could in the worst case contribute $\pm 16 \%$ to the uncertainty of the temperature-dependent $k_{1}$ values), and possible surface adsorption of $\left(\mathrm{CH}_{3}\right)_{4} \mathrm{Si}$ at the reactor walls. The first factor is considered in more detail at the low end of the temperature range where $k_{1}$ is smallest and the measurements are most vulnerable to secondary chemistry such as reaction of $\mathrm{O}$ with reaction or photolysis products. While absolute $[\mathrm{O}]_{0}$ cannot be determined in this apparatus (and is not required for finding $k_{\mathrm{psl}}$ ), for a given precursor concentration we expect [O] to increase with $F$, and thus examination of $k_{1}$ as a function of $F$ tests the extent to which the primary reaction 1 has been isolated from interfering processes. The eight $k_{1}$ values at $377 \mathrm{~K}$ do not show a significantly consistent variation with $F$ (by contrast, for example, to a previous experiment ${ }^{11}$ where a clear trend of the rate constant with $F$ was seen and corrected for by extrapolation to $F=0$ ). At higher temperatures there is no consistent variation of $k_{1}$ with $P, F$, precursor type, and $\tau_{\text {res }}$, which demonstrates that the observed kinetics there are independent of $[\mathrm{O}]_{0}$ and that there is no significant decomposition of the gas mixture at elevated temperatures. The precisions $\sigma_{T}$ and $\sigma_{k 1}$ were used to weight $1 / T$ and $\ln k_{1}$ for the Arrhenius plot shown in Figure 1. The fit to the form $A \exp \left(-E_{\mathrm{a}} / R T\right)$ is

$$
\begin{aligned}
& k_{1}=(5.1 \pm 0.7) \times \\
& 10^{-11} \exp \left(-24.1 \pm 0.6 \mathrm{~kJ} \mathrm{~mol}^{-1} / R T\right) \mathrm{cm}^{3} \mathrm{~s}^{-1}
\end{aligned}
$$

for $380 \mathrm{~K} \leq T \leq 700 \mathrm{~K}$, where the uncertainties in $A$ and $E_{\text {a }}$ are $\pm 1 \sigma .^{12}$ Consideration of the covariance, which accounts for coupling between errors in $A$ and $E_{\mathrm{a}},{ }^{13}$ leads to $2 \sigma$ precision limits for $k_{1}$ of $\pm 6 \%$ in the middle of the temperature range and $\mathbf{2 1 1 \%}$ at the extremes. There are apparently no earlier determinations of $k_{1}$ against which to check the data for systematic errors, but results obtained with the present apparatus for the reactions of $\mathrm{SiH}_{4}$ with atomic $\mathrm{O},{ }^{2} \mathrm{H},{ }^{14}$ and $\mathrm{Br}^{7}$ are in good accord with most previous determinations. An allowance of $\pm 5 \%$ for possible overlooked systematic errors here leads to an approximate $95 \%$ confidence interval of $\pm 15 \%$ of $k_{1}$.

\section{Discussion}

The rate constant $k_{1}$ and the Arrhenius parameters can be compared with those for some hydrocarbon oxidation reactions:

$$
\begin{gathered}
\mathrm{O}+\mathrm{CH}_{4} \rightarrow \mathrm{CH}_{3}+\mathrm{OH} \\
k_{6}=9.8 \times 10^{-11} \exp \left(-42 \mathrm{~kJ} \mathrm{~mol}^{-1} / R T\right) \mathrm{cm}^{3} \mathrm{~s}^{-1} \\
\mathrm{O}+\mathrm{C}_{2} \mathrm{H}_{6} \rightarrow \mathrm{C}_{2} \mathrm{H}_{5}+\mathrm{OH} \\
k_{7}=1.8 \times 10^{-10} \exp \left(-33 \mathrm{~kJ} \mathrm{~mol}^{-1} / R T\right) \mathrm{cm}^{3} \mathrm{~s}^{-1} \\
\mathrm{O}+\left(\mathrm{CH}_{3}\right)_{4} \mathrm{C} \rightarrow\left(\mathrm{CH}_{3}\right)_{3} \mathrm{CCH}_{2}+\mathrm{OH} \\
k_{8}=1.5 \times 10^{-10} \exp \left(-30 \mathrm{~kJ} \mathrm{~mol}^{-1} / R T\right) \mathrm{cm}^{3} \mathrm{~s}^{-1}
\end{gathered}
$$

Reactions 6-8 are selected because they are part of a homologous series of reactions of $\mathrm{RCH}_{3}+\mathrm{O}$ where $\mathrm{OH}$ is the known product and where all the $\mathrm{H}$ atoms have the same chemical environment. ${ }^{15}$ The $A$ factors are within a factor of 2 of $1 \times 10^{-10} \mathrm{~cm}^{3} \mathrm{~s}^{-1}$, demonstrating a fairly loose transition state for $\mathrm{H}$ atom abstraction. The fit for reaction 1 is consistent with these $A$ factors, and $\mathrm{OH}$ production is the most reasonable channel. The $E_{\mathrm{a}}$ for reaction 1 is smaller than for reactions 6-8, which might reflect the low $\mathrm{C}-\mathrm{H}$ bond energy in $\left(\mathrm{CH}_{3}\right)_{4} \mathrm{Si}$ of $415 \mathrm{~kJ} \mathrm{~mol}^{-1} .{ }^{5}$ Evans and Polanyi proposed a linear relation between the overall enthalpy change $\Delta H$ and $E_{\mathrm{a}},{ }^{16}$ which is tested here by a plot of $E_{\mathrm{a}}$ vs $D$, the C-H bond strength, ${ }^{17}$ in Figure 2a. As may be seen, this correlation is obeyed reasonably well, given the experimental uncertainties in $D$ and $E_{\mathrm{a}}$, which is further evidence that reaction 1 is analogous to the other processes.

The transition state for these abstraction reactions involves a transfer of electron density from the $\mathrm{C}-\mathrm{H}$ bond being broken to the partially formed $\mathrm{O}-\mathrm{H}$ bond, and accordingly the energy of the transition state might vary consistently with the ionization potential1.18 (IP) of $\mathrm{RCH}_{3}$. This idea is tested by the plot of Figure $2 b$. There is a reasonable correlation, with a linear 

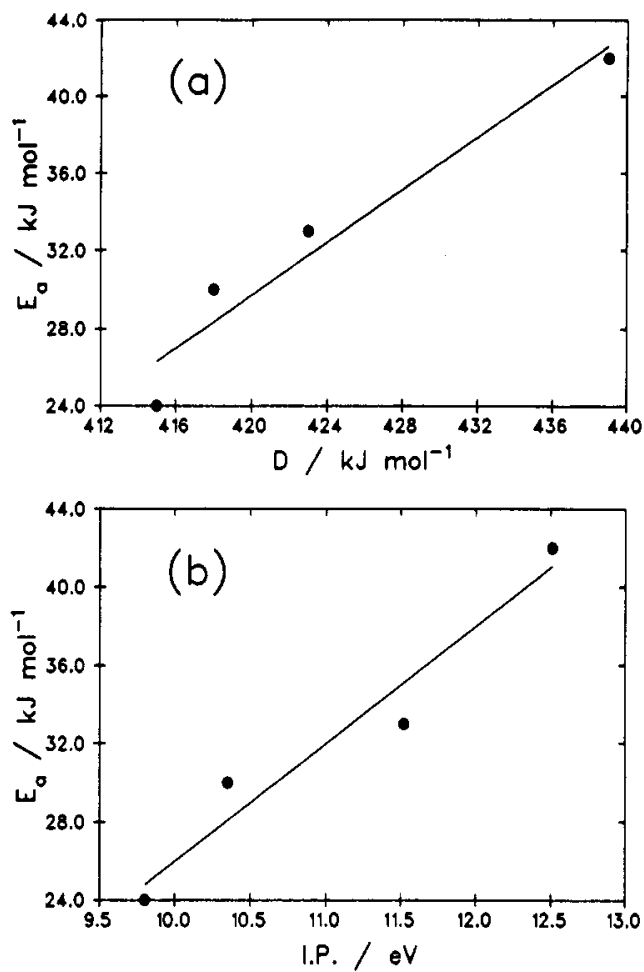

Figure 2. (a) Plot of $E_{\mathrm{a}}$ for $\mathrm{C}-\mathrm{H}$ abstraction versus $\mathrm{C}-\mathrm{H}$ bond strength, $D$. (b) Plot of $E_{\mathrm{a}}$ for $\mathrm{C}-\mathrm{H}$ abstraction versus ionization potential, IP.

relationship between $E_{\mathrm{a}}$ and IP for the abstraction of $\mathrm{H}$ from $\mathrm{RCH}_{3}$ :

$$
E_{\mathrm{a}} \approx[6 \mathrm{IP} / \mathrm{eV}-34] \mathrm{kJ} \mathrm{mol}^{-1}
$$

Provided that further work supports similar relations, e.g. for secondary and tertiary $\mathrm{H}$-atom abstraction, then such relations may be more widely applied than correlations involving $D$, because reliable IP data are available for a very broad range of hydrocarbons. ${ }^{18}$ Combination of the correlations of Figure $2 a, b$ also suggests a correlation of $D$ with IP. Our systematization of $E_{\mathrm{a}}$ for primary $\mathrm{H}$ atom abstraction is an alternative approach to that of Cohen and Westberg, ${ }^{19}$ who instead proposed a single energy barrier for this process, but with reactions 6 and 7 as exceptions.

Equation 9 can be tested via estimation of $E_{\text {a }}$ for

$$
\mathrm{O}+\left(\mathrm{CH}_{3}\right)_{3} \mathrm{CC}\left(\mathrm{CH}_{3}\right)_{3} \rightarrow\left(\mathrm{CH}_{3}\right)_{3} \mathrm{CC}\left(\mathrm{CH}_{3}\right)_{2} \mathrm{CH}_{2}+\mathrm{OH}
$$

from the IP of the alkane of $9.8 \mathrm{eV} .18$ The predicted $E_{\mathrm{a}}$ of 25 $\mathrm{kJ} \mathrm{mol}^{-1}$, when coupled with an assumed $A$ factor of $1.5 \times 10^{-10}$ $\mathrm{cm}^{3} \mathrm{~s}^{-1}$, yields $k_{10}$ at $298 \mathrm{~K}$ of about $6 \times 10^{-14} \mathrm{~cm}^{3} \mathrm{~s}^{-1}$, which is about a factor of 2 below the experimental value. ${ }^{20}$ On the unfavorable assumption that all the error is within $E_{\mathrm{a}}$, this difference corresponds to an error of only $2 \mathrm{~kJ} \mathrm{~mol}^{-1}$ in $E_{\mathrm{a}}$ and is comparable to the scatter in Figure $2 \mathrm{~b}$. Equation 9 suggests that $\mathrm{H}$ abstraction from $\mathrm{CH}_{3}$ groups in silicon-containing alkanes may be easier than previously thought. For example, Hoffmeyer et al. ${ }^{4}$ compared their $k_{2}$ measurements to $k_{10}$, but the IP of $\mathrm{Si}_{2}\left(\mathrm{CH}_{3}\right)_{6}$ of $8.27 \mathrm{eV}^{18}$ suggests that a smaller $E_{\mathrm{a}}$ for abstraction of around $16 \mathrm{~kJ} \mathrm{~mol}^{-1}$ is likely. Nevertheless, their product studies suggested that insertion dominated over abstraction, although it is possible that abstraction becomes important at elevated temperatures. Similarly, we also consider the reactions

$$
\begin{aligned}
\mathrm{O}+\left(\mathrm{CH}_{3}\right)_{3} \mathrm{SiH} & \rightarrow\left(\mathrm{CH}_{3}\right)_{3} \mathrm{Si}+\mathrm{OH} \\
& \rightarrow \mathrm{CH}_{2}\left(\mathrm{CH}_{3}\right)_{2} \mathrm{SiH}+\mathrm{OH}
\end{aligned}
$$

If $k_{11 b}$ is similar to $k_{8}$ then the branching ratio for $\mathrm{C}-\mathrm{H}$ abstraction $\left.k_{1 \mathrm{lb}} / k_{1 \mathrm{la}}+k_{1 \mathrm{lb}}\right)$ is about $4 \times 10^{-4}$ at room temperature. ${ }^{21}$ Equation 9 predicts an $E_{\text {a }}$ for abstraction similar to that for reaction 1, which leads to a larger branching ratio of around 2 $\times 10^{-3}$. Abstraction from the $\mathrm{Si}-\mathrm{H}$ bond is most likely to be the dominant channel in this case. ${ }^{1,15}$

\section{Conclusions}

The rate constant for $\mathrm{H}$ atom abstraction from tetramethylsilane has been characterized over the temperature range 380$700 \mathrm{~K}$, and the preexponential factor is of the same order as other $\mathrm{O}+$ hydrocarbon reactions, while $E_{\mathrm{a}}$ is lower. Tentative relations between $E_{\mathrm{a}}$ for a series of primary $\mathrm{H}$ atom abstraction reactions and the hydrocarbon $\mathrm{C}-\mathrm{H}$ bond strength or ionization potential have been proposed.

Acknowledgment. This work was supported by Texas Instruments, Inc., the Robert A. Welch Foundation (Grant B-1174), and the U.N.T. Organized Research Fund.

\section{References and Notes}

(1) Horie, O.: Taege, R.; Reimann, B.; Arthur, N. L.; Potzinger, P. J. Phys. Chem. 1991, 95, 4393.

(2) Taylor, C. A.; Ding, L.; Marshall, P. Int. J. Chem. Kinet., in press.

(3) Ding, L.; Taylor, C. A.; Marshall, P. 12 th International Symposium on Gas Kinetics (University of Reading, July 1992), Experimental and Theoretical Studies of Atomic H, O and Halogen Reactions with Silanes, abstract E30. 829.

(4) Hoffmeyer, H.; Potzinger, P.; Reimann, B. J. Phys. Chem. 1985, 89,

(5) Walsh, R. In The Chemistry of Organic Silicon Compounds; Patai, S., Rappoport, Z., Eds.; Wiley: New York, 1989; Chapter 5.

(6) Shi, Y.; Marshall, P. J. Phys. Chem. 1991, 95, 1654

(7) Ding, L.; Marshall, P. J. Phys. Chem. 1992, 96, 2197. 1978 .

(8) Okabe, H. Photochemistry of Small Molecules; Wiley: New York,

(9) (a) Marshall, P. Comput. Chem. 1987, 11, 219. (b) Marshall, P. Comput. Chem. 1989, 13, 103 .

(10) Irvin, J. A.; Quickenden, T. I. J. Chem. Educ, 1983, 60, 711.

(11) Ding, L.; Marshall, P. J. Am. Chem. Soc. 1992, 114, 5754.

(12) If the more scattered data at $T \approx 378 \mathrm{~K}$ are excluded the resulting fit is almost unchanged: $k_{1}=(5.4 \pm 0.9) \times 10^{11} \exp (-24.4 \pm 0.7 \mathrm{~kJ} \mathrm{~mol} / 1 / R T)$ $\mathrm{cm}^{3} \mathrm{~s}$ ?

(13) Héberger, K.; Kemény, S.; Vidóczy, T. Int.J. Chem. Kinet. 1987, 19, 171

(14) $k$ for $\mathrm{H}+\mathrm{SiH}_{4}$ was found to be $(2.1 \pm 0.3) \times 10^{11} \mathrm{~cm}^{3} \mathrm{~s}$ ' at 298 $K$ (unpublished work), in accord with values of $(2.0 \pm 0.1)$ and $(2.2 \pm 0.2)$ $\times 10^{13} \mathrm{~cm}^{3} \mathrm{~s}$ ' from Arthur, N. L.; Potzinger, P.; Reimann, B.; Steenbergen, H. P. J. Chem. Soc., Faraday Trans. 2 1989, 85, 1447 and Koshi, M.; Tamura, F.; Matsui, H. Chem. Phys. Lett. 1990, 173, 235, respectively.

(15) Herron, J. T. J.Phys. Chem. Ref. Data 1988, 17,967. An Arrhenius plot of the recommended $k_{t}$ was fitted over the range $400-700 \mathrm{~K}$ to derive the $A$ and $E_{\text {il }}$ quoted here.

(16) Evans, M. G.; Polanyi, M. Trans, Faraday Soc. 1938, 34, 11.

(17) (a) $D$ for reaction 6 is from Chase, M. W. Jr.; Davies, C. A.; Downey, J. R., Jr.; Frurip, D. J.; McDonald, R. A.; Syverud, A. N. JANAF Thermochemical Tables, 3rd ed.; J. Phys. Chem. Ref. Data 1985, 14 (Suppl. No. 1). (b) $D$ for reaction 7 is from Seakins, P. W.; Pilling, M. J.; Niiranen, J. T.: Gutman, D.: Krasnoperov, L. N. J. Phys. Chem. 1992, 96, 9847. (c) $D$ for reaction 8 is from McMillen, D. F.; Golden, D. M. Annu. Rev. Phys. Chem. 1982, 33, 493 .

(18) Lias, S. G.; Bartmess, J. E.; Liebman, J. F.; Holmes, J. L.; Levin, R. D.; Mallard W. G. J. Phys. Chem. Ref Data 1988, 17 (Suppl. No 1)

(19) Cohen, N.: Westberg, K. R. Int. J. Chem. Kinet, 1986, 18, 99

(20) Herron, J. T.; Huie, R. E. J. Phys. Chem. Ref. Data 1973, 2, 467.

(21) Based on an overall rate constant $k_{1, i}+k_{11 b}$ at $298 \mathrm{~K}$ of $2.1 \times 10$ $\mathrm{cm}^{3} \mathrm{~s}$ ' from ref 3 . Reference 1 proposed a value of $3.1 \times 10^{1}: \mathrm{cm}^{3} \mathrm{~s}$ '. 